\title{
Deteksi Objek Berwarna Merah Secara Real Time Dengan Algoritma Color Filtering
}

\author{
Yona Fransiska Dewi, Nurul Fadillah \\ Program Studi Teknik Informatika, Universitas Langsa, Indonesia \\ Email: ${ }^{1}$ yonafransiska97@gmail.com, ${ }^{2}$ nurulfadillah@unsam.ac.id
}

\begin{abstract}
Abstrak
Berbagai ilmu dan teknik pengolahan citra digital yang ada pada saat ini sangat bervariasi. Penelitian dan pengembangan telah dilakukan ke arah deteksi dan tracking objek. Warna merupakan salah satu parameter yang digunakan deteksi dan tracking objek. Manusia dapat membedakan sebuah warna, tetapi komputer belum tentu dapat mengenali warna tersebut. Teknik pengolahan citra digital yang dapat mengenali warna, salah satunya adalah color filtering. Dalam penelitian ini, Color filtering merupakan teknik pengolahan citra digital berdasarkan warna yang spesifik, mendeteksi dan tracking warna dengan memanfaatkan kamera web (webcam) dan objek berwarna merah. Object Tracking merupakan proses mengikuti suatu objek yang bergerak dan berpindah posisi, sehingga dengan demikian objek berwarna yang di tracking akan menggambar secara realtime dengan hasil warna yang dapat dipilih.
\end{abstract}

Kata Kunci: Tracking, citra, color filtering

\section{Abstract}

The various knowledge and techniques of digital image processing currently available vary greatly. Research and development has been carried out towards object detection and tracking. Color is one of the parameters used to detect and track objects. Humans can distinguish a color, but a computer may not necessarily recognize that color. Digital image processing techniques that can recognize colors, one of which is color filtering. In this study, Color filtering is a technique of processing digital images based on specific colors, detecting and tracking colors by using a web camera (webcam) and red objects. Object Tracking is the process of following an object that moves and moves position, so that the colored object being tracked will draw in realtime with the results of the colors that can be selected.

Keywords: Tracking, image, color filtering

\section{PENDAHULUAN}

Salah satu perkembangan dari penggunaan teknik computer vision adalah tracking objek. Tracking objek bertujuan untuk mendeteksi dan mengikuti posisi dari suatu objek bergerak yang diinginkan. Tracking objek banyak dibutuhkan oleh berbagai macam aplikasi vision based seperti human computer interface, kompresi/komunikasi video dan sistem keamanan. Tracking objek harus mampu mendeteksi objek yang bergerak, memfilter noise, dan gerakan-gerakan lain yang tidak diperlukan. Warna adalah kesan yang diperoleh mata dari cahaya yang dipantulkan oleh benda-benda yang dikenali nya. Warna yang diterima oleh mata dari sebuah object ditentukan oleh warna sinar yang dipantulkan oleh object tersebut. Warna - warna yang dapat ditangkap oleh mata manusia merupakan kombinasi cahaya dengan panjanh berbeda. Tracking secara real time akan menggunakan kamera web cam pada PC yang akan menyala secara otomatis agar dapat menangkap atau merekam object warna yang bergerak. Kemudian pada aplikasi ini berupa gerakan sekuen yang berpindah-pindah dari awal sampai akhir sehingga hasil dari rekaman tersebut dapat terlihat.

Color filtering adalah suatu teknik pengolahan citra berdasarkan warna yang spesifik. Cara kerja pada color filtering adalah dengan membandingkan komponen warna setiap piksel citra dengan warna spesifik. Color filtering ini digunakan pada tahapan awal untuk mendeteksi objek berbasis warna, setelah menemukan warna yang telah ditentukan, penelitian dapat dilanjutkan ke proses tracking objek. Kelebihan menggunakan metode color filtering yaitu salah satu metode yang paling sederhana melakukan penyaringan warna dalam ruang warna RGB (Red, Green, Blue) yang memberikan performa tercepat pada gambar RGB. Cara kerja dari aplikasi virtual drawing ini dengan menggunakan sebuah kamera web cam yang terdapat pada PC dengan menampilkan layer monitor yang terbagi menjadi dua, satu akan berfungsi untuk merekan secara tracking dan satu lagi berfungsi untuk menampilkan hasil tracking tersebut. Maka dari itu dibuat sebuah aplikasi pembelajaran untuk menggambar atau memberi warna dengan mengimplementasikan algoritma color filtering untuk menentukan warna object yang di tracking oleh kamera web cam.

\section{TEORITIS}

\subsection{Citra Digital}

Sebuah citra digital dapat mewakili oleh sebuah matriks yang terdiri dari M kolom $\mathrm{N}$ baris, dimana perpotongan antara kolom dan baris disebut piksel (pixel = picture element), yaitu elemen terkecil dari sebuah citra. Piksel mempunyai dua parameter, yaitu koordinat dan intensitas atau warna. Nilai yang terdapat pada koordinat $(\mathrm{x}, \mathrm{y})$ adalah $\mathrm{f}(\mathrm{x}, \mathrm{y})$, yaitu besar intensitas atau warna dari piksel di titik [1]. 


\subsection{Pengolahan Citra Digital}

Mengubah informasi citra fisik non digital menjadi digital disebut sebagai pencitraan (imaging). Citra digital dapat diolah dengan komputer karena berbentuk data numeris. Suatu citra digital melalui pengolahan citra digital (digital image processing) menghasilkan citra digital yang baru termasuk di dalamnya adalah perbaikan citra (image restoration) dan peningkatan kualitas citra (image enhancement) [1].

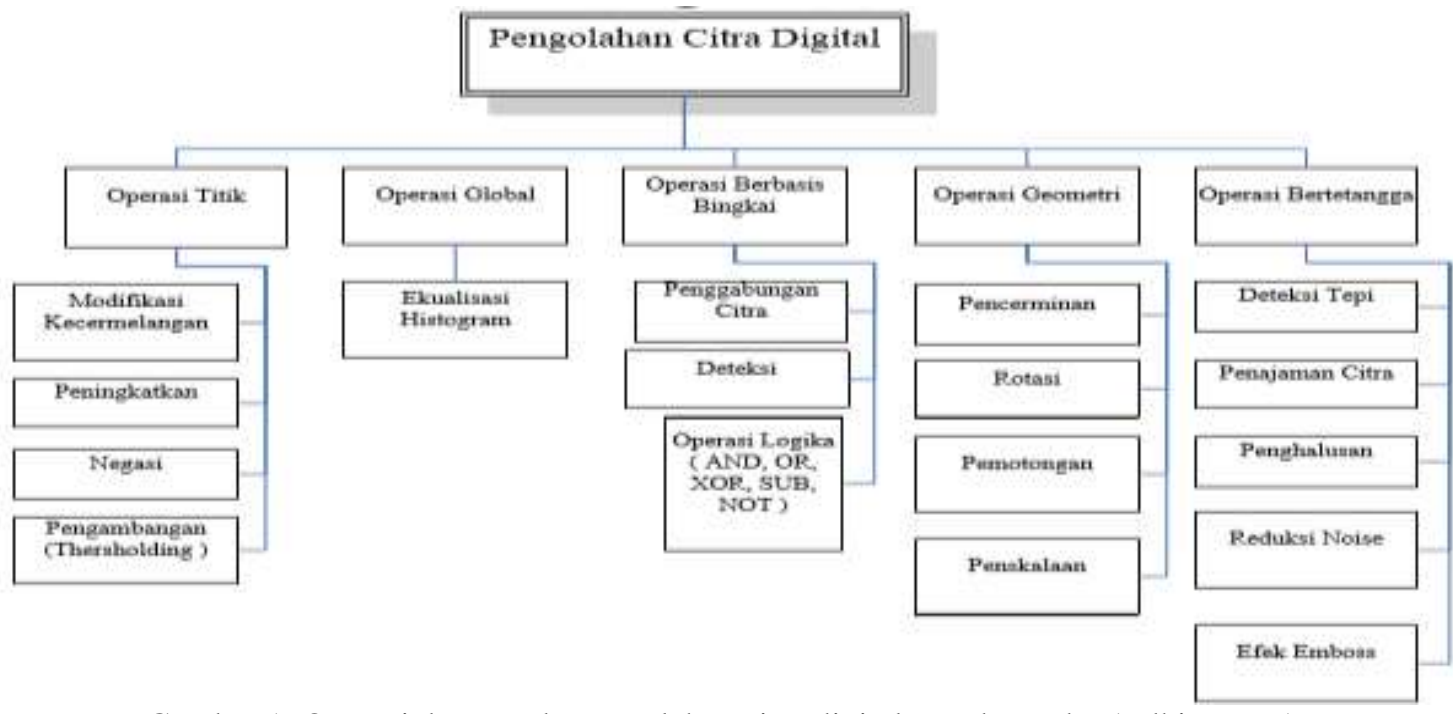

Gambar 1. Operasi dasar pada pengolahan citra digital [sumber: Eka Ardhianto] [1]

\subsection{Color Filtering}

Color Filtering adalah suatu teknikpengolahan citra yang yang dipakai untukmemanipulasi suatu citra berdasarkan warnaspesifik. Cara kerjanya adalah dengan membandingkan komponen warna setiap pixelcitra dengan warna spesifik.Apabila warnanyasesuai dengan warna spesifik komponen warnapixel tersebut dibiarkan saja.Namun, bilawarnanya tidak sesuai dengan warna spesifikmaka komponen warna pixel tersebut diubahmenjadi warna background, biasanya menjadiwarna hitam. Warna yang digunakan dalam Color Filtering dapat direpresentasikan dalam berbagai ruang warna [3].

Color Filtering adalah suatu teknik pengolahan citra yang yang dipakai untuk memanipulasi suatu citra berdasarkan warna spesifik. Cara kerjanya adalah dengan membandingkan komponen warna setiap pixel citra dengan warna spesifik. Apabila warnanya sesuai dengan warna spesifik komponen warna pixel tersebut dibiarkan saja. Namun, bila warnanya tidak sesuai dengan warna spesifik maka komponen warna pixel tersebut diubah menjadi warna background, biasanya menjadi warna hitam. Warna yang digunakan dalam Color Filtering dapat direpresentasikan dalam berbagai ruang warna. Ada beberapa ruang warna yang dikenal, antara lain RGB (Red, Green, Blue), HSV (Hue, Saturation, Value), YCbCr, dsb. HSV merupakan ruang warna yang sangat cocok untuk mengidentifikasi warna-warna dasar, dimana warna dasar ini digunakan dalam penelitian sebagai warna identifikasi robot. Selain itu, HSV menoleransi terhadap perubahan intensitas cahaya. Inilah yang menjadi keunggulan HSV dibandingkan dengan ruang warna lainnya [4].

\subsection{Webcam}

Kamera Web atau yang dikenal dengan istilah Webcam adalah sebutan bagi kamera waktu nyata yang gambarnya bisa dilihat melalui www (World Wide Web), program pengolah pesan cepat, atau aplikasi pemanggilan video. Istilah webcam merujuk pada teknologi secara umumnya, sehingga kata webcam kadang-kadang diganti dengan kata lain yang memberikan pemandangan yang ditampilkan di kamera, misalnya StreetCam yang memperlihatkan pemandangan jalan ada juga Metrocam yang memperlihatkan pemandangan panorama kota dan pedesaan, TraffiCam yang digunakan untuk memonitor keadaan jalan raya, cuaca dengan WeatherCam, bahkan keadaan gunung berapi dengan VolcanoCam. Kamera web dapat diartikan juga sebagai sebuah kamera video digital kecil yang dihubungkan ke komputer melalui port USB, port COM atau dengan jaringan Ethernet atau Wi-Fi [3].

\section{ANALISA DAN PEMBAHASAN}

Dalam pembuatan aplikasi virtual drawing ini diterapkan sebuah proses Color Filtering. Cara kerjanya adalah dengan membandingkan komponen warna setiap pixel citra dengan warna spesifik. Apabila warnanya sesuai dengan warna spesifik komponen warna pixel tersebut dibiarkan saja. Namun, bila warnanya tidak sesuai dengan warna spesifik maka komponen warna pixel tersebut diuba hmenjadi warna background. Berikut merupakan tahapan dari proses Color Filtering: 


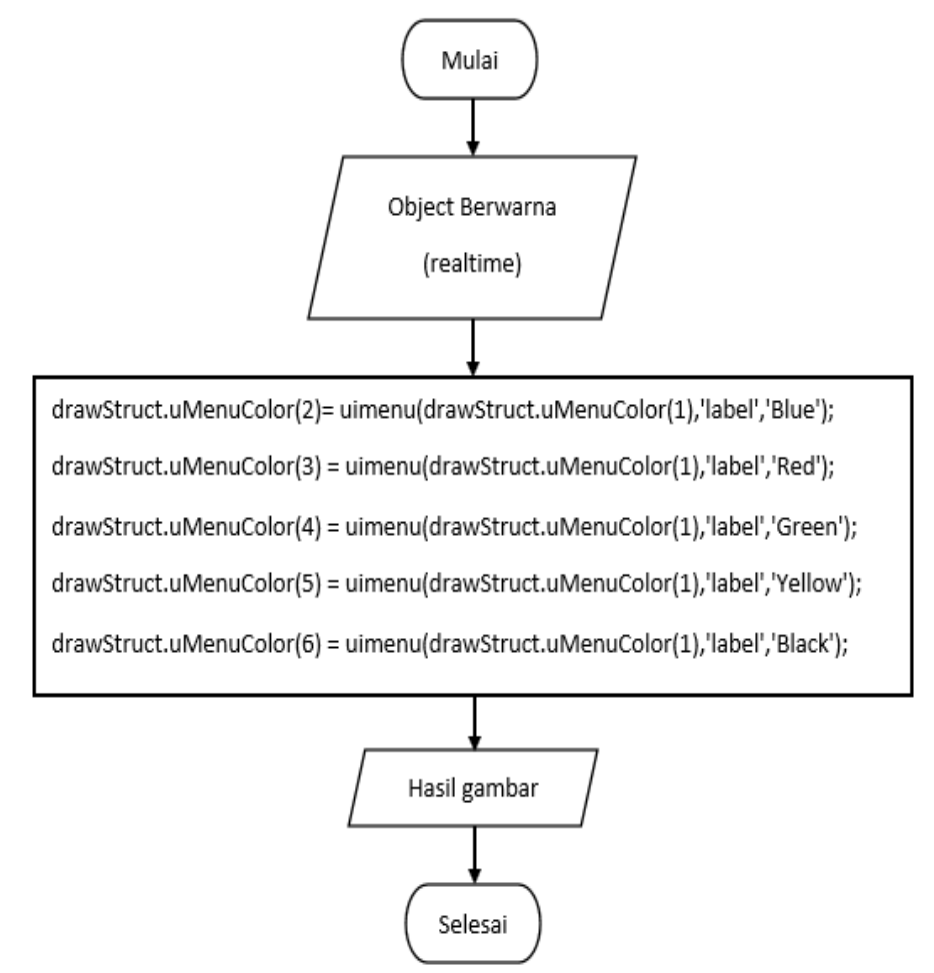

Gambar 2. Flowchat pada penelitian tracking objek berwarna secara realtime

\subsection{Open objeck berwarna (realtime)}

Proses pertama yang dilakukan adalah dengan mentracking objeck berwarna merah yang terdeteksi oleh kamera laptop (web cam) secara real time. Program akan mendeteksi object yang mempunyai warna merah saja.

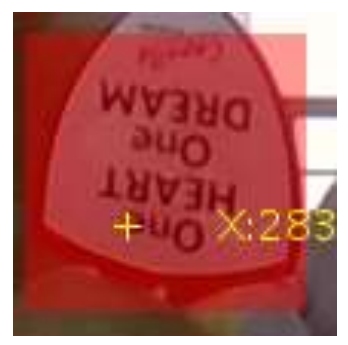

Gambar 3. Tracking objek berwarna merah

\subsection{Proses pewarnaan untuk virtual drawing}

Setelah objek berwarna ditracking secara realtime oleh kamera web cam, maka objek berwarna tersebut digerakkan untuk virtual drawing, maka pada layer hasil akan menampilkan warna biru yang merupakan hasil tracking obejk berwarna tersebut. Pada layer hasil tracking dapat memilih warna hasil nya seperti (merah, hijau, biru, kuning dan hitam) berikut dengan warna biru.

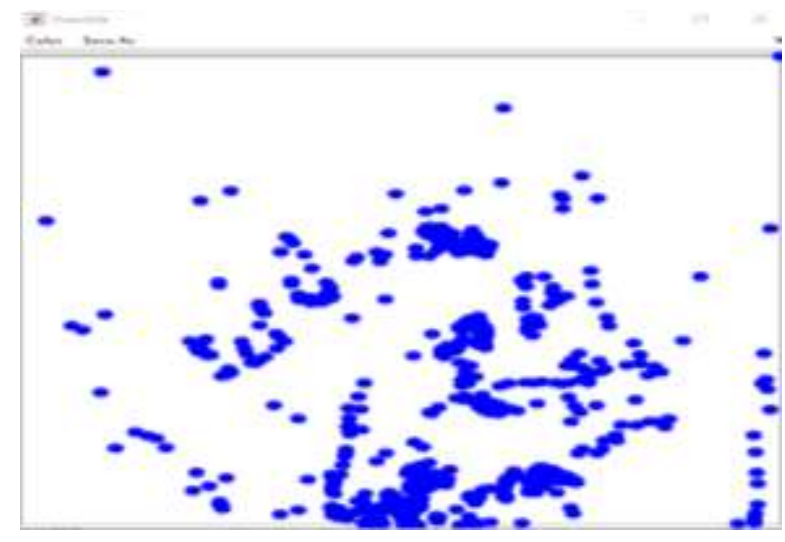

Gambar 4. Hasil tracking dengan warna pilihan biru 


\section{IMPLEMENTASI}

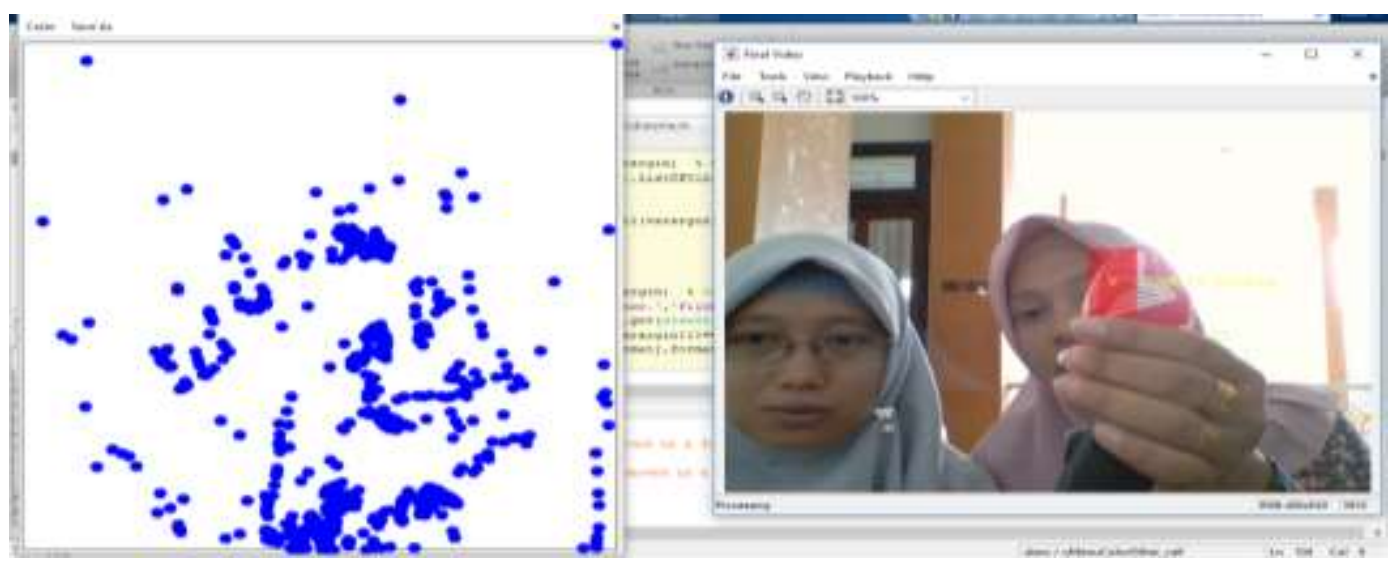

Gambar 5. Tracking objek berwarna merah (B) dan hasil tracking dengan hasil warna biru (A)

Komputer Vision didefinisikan sebagai salah satu cabang ilmu pengetahuan yang mempelajari bagaimana komputer dapat mengenali obyek yang diamati. Object Tracking adalah proses mengikuti suatu objek yang bergerak dan berpindah posisi. Color Filtering adalah suatu teknik pengolahan citra yang dipakai untuk memanipulasi suatu citra berdasarkan warna spesifik. Cara kerjanya adalah dengan membandingkan komponen warna setiap pixel citra dengan warna spesifik. Pada program diatas mula-mula aplikasi dijalankan (running) selanjutnya kamera laptop akan menyala dan melakukan tracking terhadap objek yang berwana merah. Kamera akan mencari, mendeteksi dan mentracking objek tersebut selama masih berwarna merah yang ditangkap oleh kamera tersebut. Objek berwarna merah didapatkan maka kamera akan mengikuti kemana arah objeck berwarna merah tersebut bergerak dan akan menghasilkan pada layer sebelah dengan warna yang dapat dirubah sesuai dengan yang diinginkan oleh user dalam mendrawingnya.

Dengan berbagai warna yang terdapat pada layer hasil drawingberfungsi agar virtual drawing ini tidak memerlukan aplikasi tambahan dalam proses pewarnaan.warna merah dengan sintax uMenuColor(2)=uimenu(drawStruct.uMenuColor(1),'label','Blue'); yaitu akan menampilkan hasil drawing dengan warna biru pada layer hasil. uMenuColor(2)=uimenu(drawStruct.uMenuColor(1),'label','Red'); yaitu akan menampilkan hasil drawing dengan warna merah pada layer hasil. uMenuColor(2)=uimenu(drawStruct.uMenuColor(1),'label','Green'); yaitu akan menampilkan hasil drawing dengna warna hijau pada layer hasil. uMenuColor(2)=uimenu(drawStruct.uMenuColor(1),'label','Yellow'); yaitu akan menampilkan hasil drawing dengan warna kuning. Dan uMenuColor(2)=uimenu(drawStruct.uMenuColor(1),'label','Black'); akan menampilkan warna hitam pada layer hasil. Setelah proses drawing selesai maka pada layer hasil dapat dikonversikan ke dalam format gambar (jpg, png, dam bmp) dengan cara memilih menu save as file maka hasil drawing akan disampan sesuai dengna format yang dipilih. Sintax uMenuFile(2) = uimenu(drawStruct.uMenuFile(1),'label','<.jpg>'); maka hasil drawing akan akan disimpan dengan format gambar “jpg”. uMenuFile(2) = uimenu(drawStruct.uMenuFile(1),'label','<.png >'); yaitu hasil virtual drawing disimpan dalam format "png". Dan uMenuFile $(2)=$ uimenu(drawStruct.uMenuFile(1),'label','<.bmp>'); yaitu hasil virtual drawing akan disimpan dalam format "bmp".

\section{KESIMPULAN}

Penelitian ini berhasil tracking objek secara real time dengan menggunakan metode color filtering yang dapat digunakan untuk menangkap gambar berwarna merah secara real time dan digunakan untuk menggambar warna pada layer putih.

\section{REFERENCES}

[1] Ardhianto, Eka, Hadikurniawati, Wiwien, Budiarso, Zuli. 2013. Implementasi Metode Image Subtracting dan Metode Regionprops untuk Mendeteksi Jumlah Objek Berwarna RGB pada File Video. ISSN: 0854-9524 Hal 92-93.

[2] Annisa Sulistyowati, Hariyani, YS, Novianti, Atik. 2018. Perancangan Aplikasi Pembaca Warna Dan Bentuk Berbasis Pengolahan Citra Untuk Daftar Katalog Perpustakaan. e-Proceeding of Applied Science : Vol.4, No.3 Desember 2018. ISSN: $2442-5826$ Hal 2557.

[3] Buksh Narejo, Dr. Ghous, Bharucha SP. Real Time Finger Ciunting And Virtual Drawing Using Color Detection And Shape Recognition. Pakistan. NED University of Engineering and Texhnology. NED University of Engineering and Technology Karachi, Pakistan.

[4] Khamdi, Nur, Susantok, Muhammad, Leopard, Piter. 2017. Pendeteksian Objek Bola Dengan Metode Color Filtering Hsv Pada Robot Soccer Humanoid. Vol: 6, No. 2, Juli 2017. ISSN: $2302-2949$ hal 124.

[5] Nana H, Asep, Rosmala, Dewi, Ichwan M, Indarko, RW. 2016. Implementasi Algortima Color Filtering Pada Aplikasi Gitar Virtual.Seminar Nasional Telekomunikasi dan Informatika (SELISIK 2016). 28 Mei 2016. ISSN:2503-2844 hal $255-256$. 